\title{
Diabetes mellitus in a girl with thyroid hormone resistance syndrome: a little recognized interaction between the two diseases
}

\author{
Stefano Stagi, ${ }^{1}$ Cristina Manoni, ${ }^{1}$ Valentina Cirello, ${ }^{2}$ Danila Covelli, ${ }^{2}$ Sabrina Giglio, ${ }^{3}$ \\ Francesco Chiarelli, ${ }^{4}$ Salvatore Seminara, ${ }^{1}$ Maurizio de Martino ${ }^{1}$
}

${ }^{1}$ Health Sciences Department, University of Florence, Anna Meyer Children's University Hospital, Florence; ${ }^{2}$ Department of Medical Sciences, University of Milan and Endocrine Unit, Fondazione Policlinico IRCCS, Milan; ${ }^{3}$ Genetics and Molecular Medicine Unit, Anna Meyer Children's University Hospital, Florence; ${ }^{4}$ Department of Paediatrics, University of Chieti, Chieti; Italy

\begin{abstract}
The syndrome of resistance to thyroid hormone (RTH) is characterized by elevated serum free thyroid hormones $\left(\mathrm{FT}_{4}\right.$ and $\mathrm{FT}_{3}$ ) in the presence of unsuppressed $\mathrm{TSH}$ levels, reflecting resistance to the normal negative feedback mechanisms in the hypothalamus and pituitary. The degree of resistance within peripheral tissues determines whether thyrotoxic clinical features are associated with this condition. Classic features include attention deficit hyperactivity disorder, growth delay, tachycardia, and goiter. However, other features, such as frequent ear, nose and throat infections, hearing deficit, and decreased bone mass have recently been recognized. The phenotype of RTH is variable, with most patients presenting with mild to moderate symptoms. In this report we describe a girl with familiar RTH and diabetes mellitus. This is, to our knowledge, the first report regarding this association. Nearly one year after long-term triiodothyroacetic acid (Triac) therapy, we observed a reduction of thyroid hormone levels with an amelioration of insulin resistance. The possible interactions between these disorders are discussed.
\end{abstract}

Key words: Diabetes, Genetic syndromes, Goiter, Thyroid hormone resistance

\section{INTRODUCTION}

The syndrome of resistance to thyroid hormone (RTH; MIM 188570) is characterized by elevated

\footnotetext{
Address for correspondence:

Dr. Stefano Stagi, Health Sciences Department, University of Florence, Anna Meyer Children's University Hospital, Florence, Italy, Tel.: + 39-055-5662585,

Fax: +39-055-4221012, E-mail: stefano.stagi@yahoo.it

Received 29-09-2013, Accepted 19-03-2014
}

serum free thyroid hormones (TH) in the presence of unsuppressed TSH levels, reflecting resistance to the normal negative feedback mechanisms in the hypothalamus and pituitary. ${ }^{1}$ The degree of resistance within peripheral tissues determines whether thyrotoxic clinical features are associated with this condition. ${ }^{1}$

RTH is caused by a mutation in the TH receptor (TR)- $\beta$ gene (THRB; MIM 190160). To date, more 
than 300 families with the RTH phenotype have been found to harbor mutations in this gene. ${ }^{2}$ The mutant TR interferes with the activity of normal TR to induce the clinical syndrome. ${ }^{3}$ Identification of an autosomal dominant mode of inheritance, in conjunction with the recognition that receptor mutants are functionally impaired, has led to the proposal that these abnormal proteins are able to inhibit the function of their wildtype counterparts in a dominant negative manner. ${ }^{1}$ However, sporadic de novo cases are also common, although recessive inheritance is rare. ${ }^{4}$

The phenotype of RTH is variable, with most patients presenting with mild to moderate symptoms. ${ }^{5}$ Since its first description by Refetoff et al in 1967, ${ }^{6}$ classic features have been progressively identified, including attention deficit and hyperactivity disorder, growth delay, tachycardia, and goiter. However, other features, such as frequent ear, nose and throat infections, hearing deficit, and decreased bone mass, have recently been recognized. ${ }^{5}$ As RTH patients present with elevated TH levels and goiter, frequently accompanied by some manifestations of thyrotoxicosis, the condition is often misdiagnosed as Graves' disease. However, exophthalmos has never been identified as a feature of RTH and thyroid auto-antibodies have been detected only in approximately $4 \%$ of patients. ${ }^{7}$

In these patients, an impairment of the glucose metabolism has not, to our knowledge, been reported. In this case report, we describe a girl with THR and diabetes mellitus, while we also discuss the potential mechanisms of this association.

\section{CLINICAL REPORT}

The patient, a female aged 10 years and 7 months, was referred to our Paediatric Endocrinology Unit for low body mass index (BMI) and suspected diagnosis of hyperthyroidism.

The proposita was the third-born child of a nonconsanguineous marriage delivered normally at 40 weeks after an uncomplicated pregnancy. Family history was suggestive of thyroid pathologies and type 2 diabetes mellitus (T2DM); the mother showed a history positive for goiter, hyperthyroidism, and fasting hyperglycaemia, diagnosed until adolescence. Three aunts have a history of thyroid diseases with goiter and unspecified dysthyroidism. One of these also showed impaired glucose tolerance (IGT), starting from the age of 34 years. One brother died of sudden infant death syndrome at three months of age. The other brother, 18 yrs old, was without any medical problems.

At birth, the girl's Apgar score was $10^{\mathrm{I}}-10^{\mathrm{V}}$. Birth weight was $2.6 \mathrm{Kg}$ (-1.90 SDS), length was $48 \mathrm{~cm}$ (-1.40 SDS) and head circumference $33.5 \mathrm{~cm}$ (-1.03 SDS). The neonatal congenital hypothyroidism screening was negative.

At 10 years and 7 months of age the girl weighed $26.6 \mathrm{~kg}(-1.75 \mathrm{SDS})$ and her height was $144 \mathrm{~cm}(-0.20$ SDS). BMI was 12.80 (-3.00 SDS), according Cacciari et al. ${ }^{8}$ The girl had no dysmorphic features. Her pubertal staging was B2-PH1-AH1. Her history was positive for frequent headache episodes and learning difficulty in school. At physical examination she appeared as hyperactive. There was no exophthalmos, muscle weakness or tremor. There was no erythema or onycholysis. The neurological and audiometric examinations were normal. Her blood pressure was $110 / 70 \mathrm{mmHg}$ and her pulse rate was 110 beats/min. The skeletal muscles appeared hypotrophic and the adipose tissue reduced. The patient's thyroid gland was slightly and symmetrically enlarged.

Basal hormonal investigation revealed $\mathrm{fT}_{4} 4.26$ $\mathrm{ng} / \mathrm{dL}$ (normal range: $0.8-1.9$ ), fT3 $8.02 \mathrm{pg} / \mathrm{mL}$ (normal range: 1.6-4.8), TSH $3.90 \mu \mathrm{IU} / \mathrm{mL}$ (normal range: 0.4-4). Antibodies against thyroperoxidase, thyroglobulin, and TSHR were undetectable. The fundus oculi, ECG, and echocardiography were normal.

Ultrasound examination of the neck showed an in-place, slightly enlarged thyroid gland. Bone age, performed according to the Greulich and Pyle method, was correspondent to chronological age (10 years vs. 10 years 7 months).

Other laboratory examinations showed normal haemoglobin levels (135 g/L; normal range: 120-150 $\mathrm{g} / \mathrm{L})$, mean corpuscular volume (MCV) $(75.7 \mathrm{fL}$; normal range: 75-90 fL), serum cortisol (18 mg/dL; 08 AM normal range $5-25 \mathrm{mg} / \mathrm{dL})$, adrenocorticotropic hormone (ACTH) (08 AM 35 pg/mL; normal range $9-52 \mathrm{pg} / \mathrm{mL}), 30$ 's prolactin (PRL) $(100 \mathrm{mIU} / \mathrm{L}$; normal range $63-426 \mathrm{mIU} / \mathrm{L})$, total calcium $(2.3$ $\mathrm{mmol} / \mathrm{L}$; normal range $2.2-2.7 \mathrm{mmol} / \mathrm{L}$ ), phosphate 
(1.12 mmol/L; normal range 1.09-1.4 mmol/L), 25-hydroxyvitamin D (30.5 ng/mL; normal value $>30 \mathrm{ng} /$ $\mathrm{mL}), 1,25$-dihydroxyvitamin $\mathrm{D}(65.5 \mathrm{pg} / \mathrm{mL}$; normal range: $19.9-67 \mathrm{pg} / \mathrm{mL})$; parathyroid hormone $(\mathrm{PTH})$ (37.6 pg/mL; normal range: $12-72 \mathrm{pg} / \mathrm{mL}$ ), bone alkaline phosphatase (82.3 U/L; normal range 40-140 $\mathrm{U} / \mathrm{L}$ ), osteocalcin (90 ng/mL; normal range 45-110 $\mathrm{ng} / \mathrm{mL})$, and urinary deoxypyridinoline $(46 \mathrm{nM} / \mathrm{mM}$ creatinine; normal range $30-60 \mathrm{nM} / \mathrm{mM}$ creatinine) levels. Her blood chemistry was AST 23 IU/L, ALT $36 \mathrm{IU} / \mathrm{L}, \gamma$-GTP $27 \mathrm{IU} / \mathrm{L}$, ferritin $10.5 \mathrm{ng} / \mathrm{mL}, \mathrm{HbA} 1 \mathrm{c}$ $5.6 \%$, triglycerides $138 \mathrm{mg} / \mathrm{dL}$, total cholesterol 235 $\mathrm{mg} / \mathrm{dL}$, HDL cholesterol $49 \mathrm{mg} / \mathrm{dL}$, LDL cholesterol $158 \mathrm{mg} / \mathrm{dL}$, insulin $26 \mu \mathrm{U} / \mathrm{mL}$, glycaemia $130 \mathrm{mg} / \mathrm{dL}$. No excretion of glucose in the urine was detectable.

However, an oral glucose tolerance test indicated diabetes mellitus with hyperinsulinism and insulin resistance: glycaemia was $131 \mathrm{mg} / \mathrm{dL}$ at 0 ', and 205 $\mathrm{mg} / \mathrm{dL}$ at $120^{\prime}$, whereas insulin was $34.6 \mu \mathrm{U} / \mathrm{mL}$ at $0^{\prime}$, and $78.8 \mu \mathrm{U} / \mathrm{mL}$ at $120^{\prime}$ (Table 1). Homeostasis Model Assessment - Insulin Resistance (HOMA-IR) index (11.19) and Matsuda index (1.29) indicated insulin resistance.

Coeliac disease screening was negative (IgA 129 $\mathrm{mg} / \mathrm{dL}$; anti-tissue transglutaminase (tTG) antibodies $0.5 \mathrm{U} / \mathrm{mL}$ ). The HLA was DQ2 DR3, 11 DRB3* DRw52.

Routine cytogenetic investigations revealed an apparently normal female karyotype $(46, X X)$. For the next diagnostic plan, the sequence analysis of the $T R \beta$ gene revealed a mutation in exon 9 and an amino acid alteration, namely, a substitution of valine for methonine at codon 313 (Met313Val) (Figure 1). This mutation has not, to our knowledge, been

Table 1. Thyroid hormone and TSH levels and metabolic evaluation before and after TRIAC administration

\begin{tabular}{lcc}
\hline & Before TRIAC (10 years 7 months) & After TRIAC (11 years 9 months) \\
\hline Height (SDS) & -0.20 & -0.11 \\
Weight (SDS) & -1.75 & -1.83 \\
BMI (SDS) & -3.00 & -2.78 \\
$\mathrm{FT}_{4}(\mathrm{ng} / \mathrm{dL})$ & 4.26 & 2.47 \\
$\mathrm{FT}_{3}(\mathrm{pg} / \mathrm{mL})$ & 8.02 & 5.23 \\
TSH $(\mu \mathrm{IU} / \mathrm{mL})$ & 3.90 & 2.60 \\
Total cholesterol (mg/dL & 235 & 176 \\
HDL cholesterol (mg/dL) & 49 & 53 \\
LDL cholesterol (mg/dL) & 158 & 101 \\
Triglycerides (mg/dL) & 138 & 108 \\
OGTT & & \\
Glycaemia (mg/dl) & & \\
T0' & 131 & 106 \\
T30' & 222 & 132 \\
T60' & 189 & 144 \\
T90' & 146 & 116 \\
T120' & 205 & 129 \\
Insulin $(\mu \mathrm{U} / \mathrm{mL})$ & & \\
T0' & 34.6 & 15.4 \\
T30' & 89.3 & 34.9 \\
T60' & 110.3 & 67.8 \\
T90' & 35.4 & 25.3 \\
T120' & 78.8 & 31.2 \\
HbA1c & 5.6 & 5.2 \\
\hline
\end{tabular}




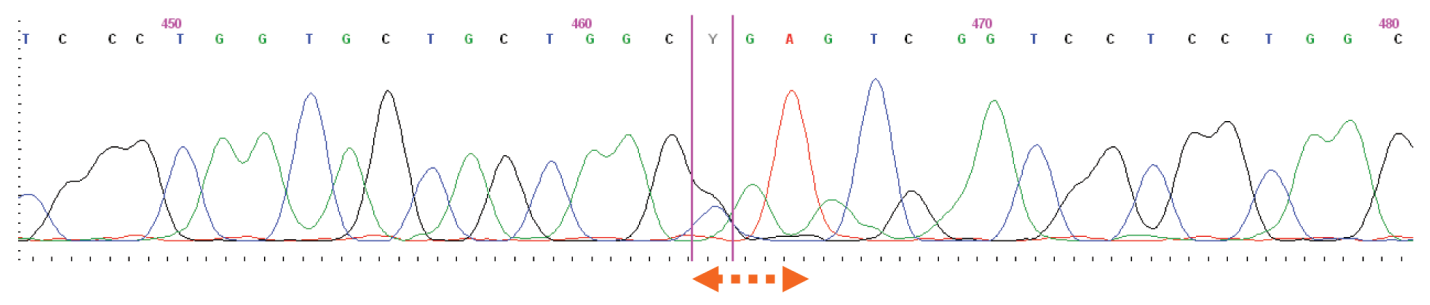

a) (PRIMER FORWARD)

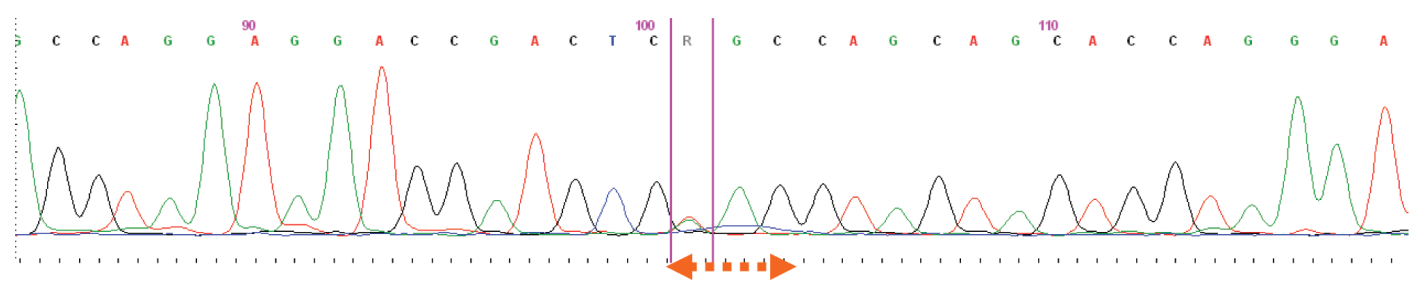

b) (PRIMER REVERSE)

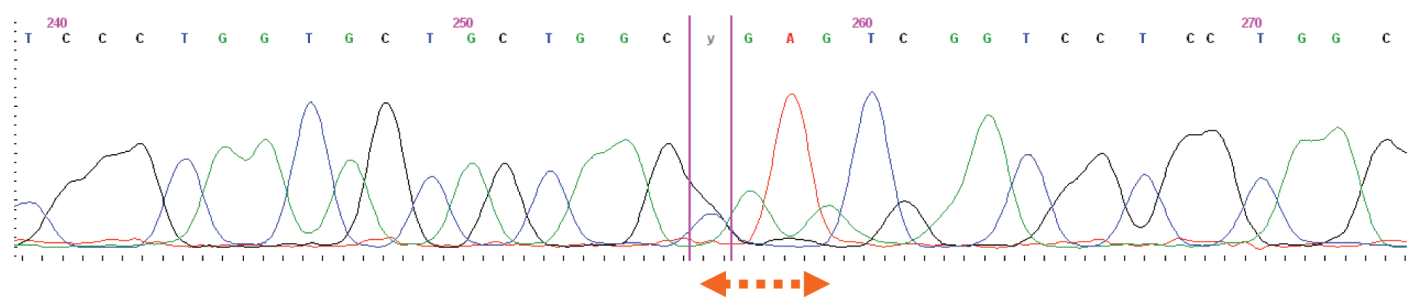

c) (PRIMER FORWARD)

Figure 1. Electropherogram of gene TR $\beta$ in the proposita (a and b) and the mother (c), showing a point mutation at codon 313 (Met313Val).

described in the literature. The same mutation was detected in the mother and in two maternal aunts (one with IGT).

Therefore, the proposita was started on a 3,5,5'-triiodothyroacetic acid (Triac) therapy at the initial dose of $1 \mathrm{mg} / \mathrm{d}$. At the same time, nutritional recommendations and interventions were also initiated for diabetes.

Almost one year after long-term Triac therapy (11 years 9 months of age), the girl weighed $30.2 \mathrm{~kg}$ (-1.83 SDS) and her height was $149.6 \mathrm{~cm}(-0.11$ SDS $)$. BMI was 13.49 (-2.78 SDS), according Cacciari et al. ${ }^{8}$ The girl had no dysmorphic features. The pubertal staging was B2-3-PH2-AH1.

We noted a reduction of thyroid hormone levels: $\mathrm{fT}_{4} 2.47 \mathrm{ng} / \mathrm{dL}, \mathrm{fT}_{3} 5.23 \mathrm{pg} / \mathrm{mL}, \mathrm{TSH} 2.60$. We also observed an amelioration of glucose and insulin metabolism: HbA1c was 5.2\%, basal glycaemia was 104 $\mathrm{mg} / \mathrm{dl}$, and basal insulin was $18.3 \mu \mathrm{U} / \mathrm{mL}$. However, triglycerides were $108 \mathrm{mg} / \mathrm{dL}$, total cholesterol 176 $\mathrm{mg} / \mathrm{dL}$, HDL cholesterol $53 \mathrm{mg} / \mathrm{dL}$, LDL cholesterol $101 \mathrm{mg} / \mathrm{dL}$. After a new oral glucose tolerance test, we hypothesized that glucose metabolism could be ameliorated by Triac treatment, possibly by improving insulin sensitivity (Table 1). In fact, basal glycaemia was $106 \mathrm{mg} / \mathrm{dL}$ (116 mg/dL at 120') and basal insulin $15.4 \mu \mathrm{U} / \mathrm{mL}\left(31.2 \mu \mathrm{U} / \mathrm{mL}\right.$ at $\left.120^{\prime}\right)$. HOMA index was 4.03 and Matsuda index 3.50.

\section{DISCUSSION}

Resistance to thyroid hormone is an uncommon disorder characterized by elevated circulating THs with nonsuppressed TSH levels, reflecting resistance within the hypothalamic-pituitary-thyroid axis but variable refractoriness to hormone action in peripheral tissues. ${ }^{9}$

Clinically, RTH can be divided into two entities: generalized (GRTH) and pituitary (PRTH) resistance. ${ }^{3}$ A molecular mechanism to explain these two 
clinical phenotypes has proven elusive and many authors have concluded that they are part of a spectrum of the same disorder..$^{10}$ However, most subjects with GRTH are either asymptomatic or have nonspecific symptoms and are deemed to be in a compensated euthyroid state. In contrast, a subset of affected individuals can exhibit some clinical features of hyperthyroidism, suggesting greater central or pituitary RTH than in peripheral tissues. ${ }^{11}$

A possible, partial, explanation may be tissuedependent TRs expression. In fact, although TR $\alpha 1$ and TR $\beta 1$ are expressed ubiquitously, TR $\alpha 1$ is expressed predominantly in the heart, bone, brain, and skeletal muscle, ${ }^{11}$ whereas TR $\beta 1$ is expressed more abundantly in liver, kidney, and thyroid. ${ }^{10}$ However, TR $\beta 2$ expression is limited to the pituitary gland, hypothalamus, retina, and inner ear. ${ }^{10}$

In the murin pancreas, $\mathrm{TR} \alpha 1$ is mainly expressed in $\alpha$-cells. ${ }^{12}$ On the other hand, $T_{3}$ rapidly induces Akt activation, with specific non-genomic action, in pancreatic $\beta$-cells via TR $\beta 1$. Thus, $T_{3}$ could be considered a survival factor protecting islet $\beta$-cells from apoptosis. ${ }^{13}$ Besides this, the predominance of an $\alpha$ receptor isoform in skeletal muscle may explain retention of sensitivity to $\mathrm{TH}$ by this target tissue, though some observations also support the notion that skeletal muscle is less refractory to $\mathrm{TH}$ action than the hypothalamic-pituitary axis in $\mathrm{RTH} .{ }^{11}$

Patients with RTH usually present with goiter and a euthyroid or mildly hypothyroid metabolic state. ${ }^{14}$ However, the clinical presentation of the disease may be hypothyroidism, with symptoms such as delayed growth, cognitive dysfunction, and hypercholesterolaemia and, concurrently, signs consistent with hyperthyroidism, including tachycardia, weight loss, attention deficit-hyperactivity disorder, and advanced bone age. ${ }^{15}$ The hypothyroid-like effects are presumably the consequence of mutant TR $\beta$ interference with, or inhibition of, normal $\mathrm{T}_{3}$ signalling pathways, whereas the signs reflective of hyperthyroidism result from the elevated $\mathrm{T}_{3}$ driving the activity of the TR $\alpha 1$ isoform. ${ }^{15}$

The secondary occurrence of T2DM with pituitary, adrenal, and/or thyroid diseases is a recurrent observation. ${ }^{16}$ Indeed, IGT and overt diabetes mellitus have frequently been associated with acromegaly, hypercortisolism, and hyperthyroidism. ${ }^{16}$
Several studies evaluating the genomic and nongenomic effects of $\mathrm{TH}$ on insulin secretion have been conducted in order to clarify the mechanism(s) behind the IGT observed in hyperthyroidism. ${ }^{17}$ For example, in rats treated with high and low doses of $\mathrm{T}_{4}$, fasting blood glucose levels were increased, but serum insulin levels were similar to those of controls. ${ }^{17}$ By contrast, in rats treated only with high doses of $\mathrm{T}_{4}$, after an oral glucose load, blood glucose levels were increased, but serum insulin levels were decreased. ${ }^{17}$ Hence, in animals, a deficient pancreatic $\beta$-cell response to glucose, rather than insulin resistance, seems to be responsible for the abnormal glucose tolerance. ${ }^{17}$

Notwithstanding, in humans, a recent study of Mitchell et al showed that RTH subjects exhibited insulin resistance as reflected by HOMA-IR. ${ }^{11}$ In fact, in a subgroup of five RTH patients undergoing an OGTT, the ISI tended to be significantly lower and HOMA significantly higher than controls, clearly indicating the presence of an insulin-resistance. ${ }^{11}$

One possible explanation for these discrepant results between animal models and humans may be that besides stimulating muscle fat oxidation and mitochondrial energy uncoupling in skeletal muscle, $\mathrm{TH}$ also promotes myocellular lipogenesis. A further possibility is that the liver RTH action might influence hepatic insulin sensitivity. ${ }^{11}$

A key phenotype associated with T2DM in humans is impaired mitochondrial oxidative metabolism in skeletal muscle, a pattern potentially contributing to increased lipid accumulation and impaired metabolic flexibility, in turn, central features of both insulin resistance and diabetes. ${ }^{18}$ In fact, the insulin-resistant state with hyperglycaemia may also be due to $\mathrm{TH}$ effects on mitochondrial content and activity, which is important for steroidogenesis as well as insulin secretion and action. ${ }^{19,20}$

However, in thyrotoxicosis, insulin levels are determined by two key factors: increased release of biologically inactive insulin precursors and increased insulin breakdown. $\beta$-cell response to a meal in patients with Graves' disease is characterized by a high proinsulin output in the hyperglycaemic state. ${ }^{21}$ The ratio of C-peptide to proinsulin is decreased, suggesting a defect in the cleaving process. ${ }^{22}$ The increase in cardiac output in hyperthyroidism leads to increased 
glomerular filtration rate and therefore increased insulin clearance. The combination of increased proinsulin secretion and increased insulin clearance results in a reduced steady state of circulating insulin in hyperthyroidism (Figure 2).

In addition to these secretion and clearance alterations, overweight hyperthyroid women lose their first-phase response to hyperglycaemia, demonstrating lower insulin peaks after intravenous glucose challenge, similar to what is observed in patients with early T2DM. ${ }^{23}$

Finally, an interesting aspect of our case report may be the possible effect, certainly also associated with changes related to the lifestyle of our patient, of Triac treatment on glucose metabolism. Although there is to date no scientific elucidation of the action of Triac on the insulinaemic metabolism, it is known that Triac has a higher affinity for TR $\beta 1 .{ }^{24}$ However, Triac inhibits leptin secretion and expression in white and brown adipocytes, whereas insulin has the opposite effect. ${ }^{25}$ In particular, leptin exerts antidiabetic actions that are independent of its regulation of body weight and food intake, ${ }^{26}$ correcting diabetes

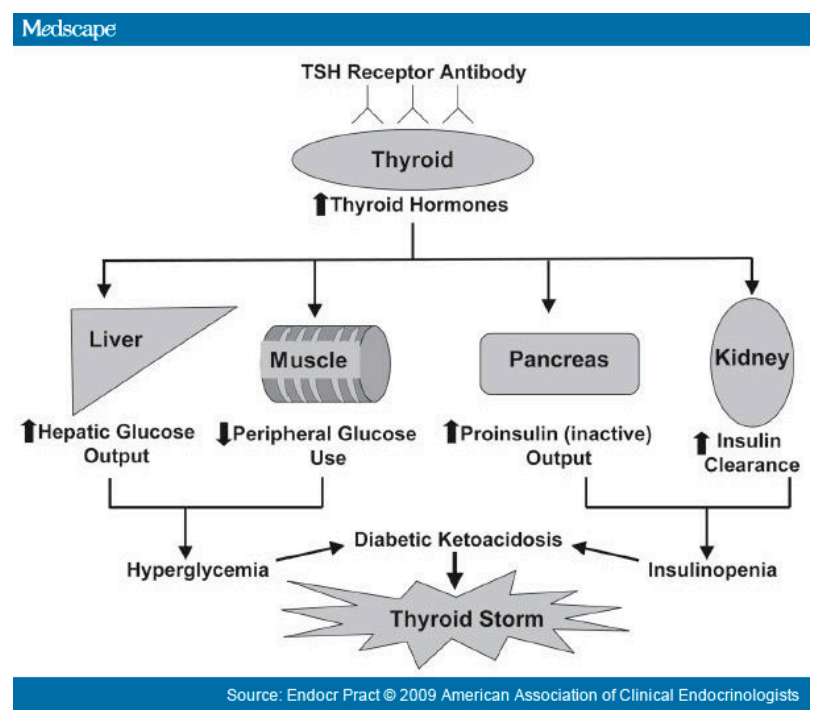

Figure 2. The effects of excess thyroid hormone on various organ systems resulting in altered glucose metabolism, potentially leading to diabetic ketoacidosis and thyroid storm. Thyroid hormone increases hepatic glucose output, decreases peripheral glucose disposal, increases inactive insulin secretion by the pancreas, and increases insulin clearance by the kidney. TSH indicates thyrotropin. in animal models of type 1 and type 2 diabetes. In addition, long-term leptin replacement therapy seems to improve glycaemic control as well as insulin sensitivity in patients with severe insulin resistance due to lipodystrophy. ${ }^{26}$

In conclusion, our data seem to show that some patients with RTH may develop an impaired glucose metabolism. We therefore suggest that glucose metabolism should be investigated in all patients with RTH.

\section{REFERENCES}

1. Gurnell M, Rajanayagam O, Agostini M, et al, 1999 Three novel mutations at serine 314 in the thyroid hormone beta receptor differentially impair ligand binding in the syndrome of resistance to thyroid hormone. Endocrinology 140: 5901-5906.

2. Refetoff S, 2005 Resistance to thyroid hormone. In: Braverman LE, Utiger RE (eds), Werner and Ingbar's the thyroid: a fundamental and clinical text. Philadelphia: Lippincott, Williams and Wilkins; pp, 1109-1129.

3. Safer JD, Langlois MF, Cohen R, et al, 1997 Isoform variable action among thyroid hormone receptor mutants provides insight into pituitary resistance to thyroid hormone. Mol Endocrinol 11: 16-26.

4. Takeda K, Sakurai A, DeGroot LJ, Refetoff S, 1992 Recessive inheritance of thyroid hormone resistance caused by complete deletion of the protein-coding region of the thyroid hormone receptor-beta gene. J Clin Endocrinol Metab 74: 49-55.

5. Refetoff S, Weiss RE, Usala SJ, 1993 The syndromes of resistance to thyroid hormone. Endocr Rev 14: 348-399.

6. Refetoff S, DeWind LT, DeGroot LJ, 1967 Familial syndrome combining deaf-mutism, stuppled epiphyses, goiter and abnormally high PBI: possible target organ refractoriness to thyroid hormone. J Clin Endocrinol Metab 27: 279-294.

7. Kourides IA, Pekonen F, Weintraub BD, 1980 Absence of thyroid-binding immunoglobulins in patients with thyrotropin-mediated hyperthyroidism. J Clin Endocrinol Metab 51: 272-274.

8. Cacciari E, Milani S, Balsamo A, et al, 2006 Italian cross-sectional growth charts for height, weight and BMI (2 to 20 yr). J Endocrinol Invest 29: 581-593.

9. Hamon P, Bovier-Lapierre M, Robert M, Peynaud D, Pugeat M, Orgiazzi J, 1988 Hyperthyroidism due to selective pituitary resistance to thyroid hormones in a 15-month-old boy: efficacy of D-thyroxine therapy. J Clin Endocrinol Metab 67: 1089-1093.

10. Beck-Peccoz P, Chatterjee VK, 1994 The variable clinical phenotype in thyroid hormone resistance syndrome. Thyroid 4: 225-232. 
11. Mitchell CS, Savage DB, Dufour S, et al, 2010 Resistance to thyroid hormone is associated with raised energy expenditure, muscle mitochondrial uncoupling, and hyperphagia. J Clin Invest 120: 1345-1354.

12. Zinke A, Schmoll D, Zachmann M, et al, 2003 Expression of thyroid hormone receptor isoform alpha1 in pancreatic islets. Exp Clin Endocrinol Diabetes 111: 198-202.

13. Verga Falzacappa C, Petrucci E, Patriarca V, et al, 2007 Thyroid hormone receptor TRbeta 1 mediates Akt activation by T3 in pancreatic beta cells. J Mol Endocrinol 38: 221-233.

14. Kopp P, Kitajima K, Jameson JL, 1996 Syndrome of resistance to thyroid hormone: insights into thyroid hormone action. Proc Soc Exp Biol Med 211: 49-61.

15. Zhang XY, Kaneshige M, Kamiya Y, Kaneshige K, McPhie P, Cheng SY, 2002 Differential expression of thyroid hormone receptor isoforms dictates the dominant negative activity of mutant Beta receptor. Mol Endocrinol 16: 2077-2092.

16. Resmini E, Minuto F, Colao A, Ferone D, 2009 Secondary diabetes associated with principal endocrinopathies: the impact of new treatment modalities. Acta Diabetol 46: 85-95.

17. Fukuchi M, Shimabukuro M, Shimajiri Y, et al, 2002 Evidence for a deficient pancreatic beta-cell response in a rat model of hyperthyroidism. Life Sci 71: 1059-1070.

18. Crunkhorn S, Patti ME, 2008 Links between thyroid hormone action, oxidative metabolism, and diabetes risk? Thyroid 18: 227-237.

19. Stark R, Roden M, 2007 ESCI Award 2006. Mitochondrial function and endocrine diseases. Eur J Clin Invest 37: 236-248.

20. Abdullah N, Al-Khalidi O, Brown KJ, Reid J, Cheetham TD, 2008 Prolonged honeymoon phase in an adolescent with diabetes and thyrotoxicosis provides support for the accelerator hypothesis. Pediatr Diabetes 9: 417-419.

21. Bech K, Damsbo P, Eldrup E, et al, 1996 beta-cell function and glucose and lipid oxidation in Graves' disease. Clin Endocrinol (Oxf) 44: 59-66.

22. Beer SF, Parr JH, Temple RC, Hales CN, 1989 The effect of thyroid disease on proinsulin and C-peptide levels. Clin Endocrinol (Oxf) 30: 379-383.

23. Ohguni S, Notsu K, Kato Y, 1995 Correlation of plasma free thyroxine levels with insulin sensitivity and metabolic clearance rate of insulin in patients with hyperthyroid Graves' disease. Intern Med 34: 339-341.

24. Takeda T, Suzuki S, Liu RT, DeGroot LJ, 1995 Triiodothyroacetic acid has unique potential for therapy of resistance to thyroid hormone. J Clin Endocrinol Metab 80: 2033-2040.

25. Medina-Gomez G, Calvo RM, Obregón MJ, 2004 T3 and Triac inhibit leptin secretion and expression in brown and white rat adipocytes. Biochim Biophys Acta 1682: 38-47.

26. Coppari R, Bjørbæk C, 2012 Leptin revisited: its mechanism of action and potential for treating diabetes. Nat Rev Drug Discov 11: 692-708. 